\title{
Quimioprofilaxis en coqueluche: ¿Sacar agua a canastos?
}

\author{
José Cofré Guerra
}

Hospital Luis Calvo Mackenna

Unidad de Infectología

Recibido: 04-12-05 Aceptado: 06-01-06

Correspondencia a: José Cofré Guerra pepecofre@123.cl

\section{Pertussis chemoprophylaxis: a sterile effort?}

Pertussis chemoprophylaxis is indicated for contacts at risk of death or of severe complications if infected with Bordetella pertussis; e.g. neonates and infants $<12$ months of age, elderly individuals, individuals with cardiac and/or respiratory insufficiency, and pregnant women during their third trimester of pregnancy (in order to protect their offspring). Available evidence indicates that PChP is effective and thus recommendable for high risk household contacts within a 21 day window after the beginning of symptoms of the index case, and if no secondary case has occurred, recommendation that may be extended to high risk individuals that cohabit with an index case at hospital, daycare centers or institutionalized elderly people. Bordetella pertussis can be transmitted by respiratory droplets that can travel further than the critical distance of 1.5 meters. This long distance transmissibility is relevant when considering who should receive prophylaxis during a nosocomial outbreak. Current evidence supports the use of macrolides and azalides for Pertussis chemoprophylaxis; seven days of erythromycin or clarithromycin and five days of azythromycin are sufficient to eradicate $B$. pertussis.

Key words: Bordetella pertussis, chemoprophylaxis; macrolides; azalides.

Palabras claves: Bordetella pertussis, quimioprofilaxis; macrólidos.
$\mathrm{E}$ ste es un tema controvertido en la literatura médica, que ha traído como consecuencia confusión entre los médicos tratantes y epidemiólogos encargados de dictar pautas para la aplicación de quimioprofilaxis (QP).

Es nuestra preocupación que el uso indiscriminado de macrólidos en una comunidad se traduce en el mediano plazo en incremento en la circulación de cepas resistentes de Streptococcus pyogenes y Streptococcus pneumoniae $e^{1-3}$. En algunos países se han alcanzado cifras alarmantes de resistencia a eritromicina, por ejemplo, para $S$. pyogenes $20 \%$ en Finlandia ${ }^{4}$ y España $^{5}$ y sobre $60 \%$ en Japón ${ }^{6}$ y en el caso de $S$. pneumoniae bordea el $30 \%$ tanto en E.U.A. ${ }^{7}$ como en países europeos ${ }^{8}$. Las últimas comunicaciones chilenas que vigilan la susceptibilidad in vitro a eritromicina de estas dos especies expresan las siguientes cifras:

Para Streptococcus pyogenes: V. Prado y cols (2001) ${ }^{9}$ : 13,4\%, E. Palavecino $(2001)^{10}: 7,2 \%$, R. Camponovo $(2002)^{11}: 6,1 \%$

Para Streptococcus pneumoniae: Laboratorio de Referencia, Instituto de Salud Pública (1999-2001) ${ }^{12}$ según comunicación de P. González: 5,8-10,0\%, E. Palavecino y cols (2002) $)^{13}: 8 \%$, R. Vergara y cols $(2002)^{14}$ : $19,4 \%$, M. Skarmeta y cols $(2005)^{15}: 30,4 \%$.

Por fortuna esta no es una amenaza significativa sobre Bordetella pertussis, la que sigue siendo universalmente susceptible a macrólidos; a la fecha hay sólo 3 reportes en resistencia a macrólidos, cada uno comunicando el aislado de una cepa resistente a eritromicina $^{16-18}$. En Chile, Pumarino y cols ${ }^{19}$ ha dado a conocer el único estudio nacional de susceptibilidad de $B$. pertussis a macrólidos sin demostrar resistencia a eritromicina en 67 cepas estudiadas. ¿Cuánto tiempo transcurrirá hasta que la resistencia suceda en nuestro medio?

Esta mini-revisión aspira a clarificar algunos conceptos clínico-epidemiológicos de los cuales se desprendan recomendaciones más racionales y acotadas para la prescripción de $\mathrm{QP}$ en coqueluche, atenuando así el impacto del uso indiscriminado de macrólidos en la comunidad sobre el perfil de resistencia de $S$. pyogenes y $S$. pneumoniae.

\section{¿Qué recomiendan guías clínicas en otras latitudes sobre la quimioprofilaxis en coqueluche?}

En la Tabla 1 se resumen las guías elaboradas por la Academia Americana de Pediatría (American Academy of Pediatrics - AAP) ${ }^{20}$, usadas habitualmente como el principal referente en nuestro medio, y guías elaboradas por autoridades correspondientes en Australia ${ }^{21}$, Reino Unido ${ }^{22}$ y Canadá ${ }^{23}$, las que representan pensamientos diferentes al de la AAP. Esta selección y citas 
Tabla 1. Recomendaciones para la aplicación de quimioprofilaxis en coqueluche, en distintas naciones.

\begin{tabular}{|c|c|c|c|c|c|}
\hline Item & $\begin{array}{l}\text { Academia Americana } \\
\text { de Pediatría } 2003\end{array}$ & Australia 2003 & Reino Unido 2002 & Canadá 2003 & $\begin{array}{l}\text { Ministerio de } \\
\text { Salud de Chile } \\
1998\end{array}$ \\
\hline Grupo a proteger & $\begin{array}{l}\text { Contactos cercanos en el } \\
\text { el hogar } u \text { otros }\end{array}$ & $\begin{array}{l}\text { Grupos de riesgo y } \\
\text { altamante expuestos: } \\
\text { lactante bajo } 12 \text { meses, } \\
\text { lactante mayor con menos } \\
\text { de } 3 \text { dosis de vacuna, } \\
\text { mujer con embarazo } \\
>36 \text { semanas }\end{array}$ & $\begin{array}{l}\text { Grupos de riesgo y } \\
\text { altamante expuestos } \\
\text { (hogar, pacientes } \\
\text { institucionalizados): RN, } \\
\text { niños hasta } 5 \text { años con } \\
\text { vacunación incompleta, } \\
\text { asmáticos, cardiópatas, } \\
\text { inmunocomprometidos }\end{array}$ & $\begin{array}{l}\text { Contactos en hogar: si } \\
\text { existe un RN o lactante } \\
\text { bajo un año de edad o } \\
\text { mujer embarazada > } 36 \\
\text { semanas. Contactos fuera } \\
\text { del hogar: sólo a personas } \\
\text { vulnerables expuestas cara } \\
\text { a cara por > una hora: }\end{array}$ & $\begin{array}{l}\text { Contactos } \\
\text { cercanos }\end{array}$ \\
\hline Comentario & & $\begin{array}{l}\text { Iniciar antes de } 21 \text { ds desde } \\
\text { inicio caso índice }\end{array}$ & & $\begin{array}{l}\text { Vulnerable: RN, mujer } \\
\text { embarazada }<36 \\
\text { semanas, lactante bajo un } \\
\text { año de edad }\end{array}$ & \\
\hline Fármacos & Eritromicina & Eritromicina & Eritromicina & Eritromicina & Eritromicina \\
\hline Plazo & 14 días & 7 días & 7 días & 7 días & 7 días \\
\hline Fármaco & Claritromicina & Claritromicina (de excepción) & & Claritromicina & \\
\hline Plazo & 7 días & 7 días & & 7 días & \\
\hline Fármaco & Azitromicina & & & Azitromicina & \\
\hline Plazo & 5 días & & & 5 días & \\
\hline Fármaco & Cotrimoxazol & & & & \\
\hline Plazo & no definido & & & & \\
\hline Refs: $20-24$ & & & & & \\
\hline
\end{tabular}

han sido hechas con el expreso objeto de poner de manifiesto que en la QP de coqueluche no está dicha la última palabra. Se incluye en esta Tabla la normativa vigente en Chile al año $2005^{24}$.

Conclusión: Existen discrepancias en estas guías en términos de en quiénes aplicar QP, qué fármacos emplear, y los plazos de prescripción.

\section{¿Cuán contagiosa es la coqueluche?}

Históricamente se consideró a esta afección como una enfermedad "obligada de la infancia" con tasas de ataque en la comunidad de $80-100 \%$ en la época prevacunación ${ }^{25}$. En población vacunada -teniendo presente la gran variabilidad de eficacia descrita para distintas vacunas "celulares"- la tasa de ataque sigue siendo significativa y alcanza a $50-80 \% 0^{26-27}$. Estudios contemporáneos efectuados en el seno de hogares han permitido medir la contagiosidad en comunidades vacunadas o entre adultos que referían haber tenido la enfermedad en su infancia. En este escenario, la tasa de ataque medida es de $\sim 40 \%$ con variaciones significativas según la edad de los expuestos: $80-90 \%$ bajo 1 año, $14 \%$ en adultos sobre 40 años ${ }^{28}$. Ahondando más, la tasa de ataque secundario es de $20 \%(65-70 \%$ en lactantes y $6 \%$ sobre 40 años de edad). El 60\% de estos casos secundarios se presentará antes de 15 días de iniciarse los síntomas en el caso índice ${ }^{28}$.

Conclusión. La coqueluche es altamente contagiosa, en especial en lactantes $\mathrm{y}$, en forma independiente del estado de vacunación. Puede afectar a personas de cualquier edad.

\section{¿Cómo se transmite la infección por Bordetella pertussis?}

Se ha afirmado que la infección se transmite por gotitas de Flügge (saliva) ${ }^{29}$ y que, según las recomendaciones del CDC de Atlanta, E.U.A., bastaría un metro de distancia entre el enfermo-fuente y el susceptible para evitar su contagio ${ }^{30}$. En una investigación reciente, N. Aintablian y cols ${ }^{31}$ han demostrado, em- 
pleando filtros ad-hoc para la recolección de muestras, que en torno a un paciente internado por coqueluche en una unidad de aislamiento, se puede detectar ADN de $B$. pertussis en el ambiente aéreo, con facilidad, hasta una distancia de $2 \mathrm{mts}$ desde su cara, y que aún a $4 \mathrm{mts}$ el aire filtrado de la habitación detecta en algunos ensayos este ADN. Expresamente los autores comentan que este hallazgo no permite obtener conclusiones sobre la viabilidad de $B$. pertussis en este protocolo y advierten que obviamente, no se puede concluir que la contagiosidad del paciente alcance hasta los 4 metros desde la fuente emisora, pero queda sembrada la duda.

Conclusión: El modelo experimental sugiere fuertemente el papel de los aerosoles en la difusión aérea de $B$. pertussis, poniendo en duda la recomendación entregada por el CDC. Parece prudente que un paciente que requiere hospitalización sea internado en régimen de aislamiento aéreo hasta dejar de ser contagioso bajo el efecto del tratamiento antimicrobiano. Por otra parte, en caso de confirmarse el diagnóstico de coqueluche en un paciente que fuera ingresado en una sala colectiva con otro diagnóstico inicial, podría considerarse en riesgo de contagio (= genuino contacto) a los pacientes vecinos, hasta un radio de $4 \mathrm{mts}$ en torno a la cabeza del caso índice. Hasta el momento ha prevalecido en nuestro país la recomendación, que fuera ratificada recientemente por el CDC de Atlanta, E.U.A., de practicar aislamiento de gotitas para los casos de coqueluche $^{31 \mathrm{a}}$

\section{¿Es la enfermedad de una severidad tal que justifique una quimioprofilaxis?}

Una acabada descripción recientemente hecha de la enfermedad en población no vacunada permite responder esta pregunta. Durante una evaluación compa- rativa de vacunas acelulares anti-pertussis efectuada en Alemania, U. Heininger y cols ${ }^{32}$ hicieron una dirigida observación clínica de la enfermedad "cultivo-positivo" en 1.640 niños. En la Tabla 2 se reproduce el tipo y frecuencia de complicaciones por ellos descrita, como también la letalidad de la enfermedad en estas condiciones. Allí queda en evidencia que:

- La letalidad global actual de la coqueluche en una población "virgen" es baja ( 1 caso en 1.640 pacientes vigilados, $0,1 \%$ en esta serie).

- Las complicaciones se presentan en aproximadamente $6 \%$ de los pacientes.

- En los lactantes hasta 12 meses de vida se concentra el mayor riesgo de presentar complicaciones graves (apneas, falla cardiopulmonar) y/o de fallecer por la enfermedad.

Estos hallazgos han sido corroborados por estudios de vigilancia de coqueluche en Canadá ${ }^{33}$ y E.U.A. ${ }^{34}$.

Por otra parte, se ha comunicado la mala tolerancia de la coqueluche en personas de la tercera edad, llegando a producirse casos fatales a raíz de accidentes vasculares encefálicos provocados por los accesos de tos $^{35}$. Se agrega como un grupo vulnerable a los pacientes que padecen de afecciones cardiopulmonares crónicas en el límite de su capacidad funcional, aunque esta recomendación nace de la opinión de expertos.

Conclusión: Los mayores esfuerzos preventivos, tanto vacunación como QP, debieran focalizarse en proteger a los niños bajo 12 meses de edad o a sus contactos cercanos que pudieran representar una fuente eficiente de contagio para estos lactantes. Constituyen también grupos de riesgo los senescentes y los pacientes con afecciones crónicas cardiopulmonares que se traducen en limitada capacidad funcional.

\begin{tabular}{|c|c|c|c|c|c|c|c|c|c|c|c|c|}
\hline \multirow[t]{2}{*}{ Complicación } & \multicolumn{2}{|c|}{$\begin{array}{l}<6 \text { m } \\
\text { (n: } 63)\end{array}$} & \multicolumn{2}{|c|}{$\begin{array}{l}\text { 6-12 m } \\
\text { (n: 59) }\end{array}$} & \multicolumn{2}{|c|}{$\begin{array}{l}\text { 1-4 años } \\
\text { (n: 610) }\end{array}$} & \multicolumn{2}{|c|}{$\begin{array}{l}\text { 4-9 años } \\
\text { (n: 846) }\end{array}$} & \multicolumn{2}{|c|}{$\begin{array}{c}>9 \text { años } \\
\text { (n: 62) }\end{array}$} & \multicolumn{2}{|c|}{$\begin{array}{c}\text { Total } \\
\text { (n: } 1.642)\end{array}$} \\
\hline & n & (\%) & n & $(\%)$ & n & $(\%)$ & n & $(\%)$ & n & $(\%)$ & n & $(\%)$ \\
\hline Neumonía & 2 & $(3,2)$ & - & - & 8 & $(1,3)$ & 18 & $(2,1)$ & - & - & 28 & $(1,7)$ \\
\hline Apnea/cianosis & 10 & $(15,9)$ & 1 & $(1,7)$ & - & & 1 & $(0,1)$ & - & & 12 & $(0,7)$ \\
\hline Hipoalimentación/vómitos intensos & 2 & $(3,2)$ & - & - & 2 & $(0,3)$ & 2 & $(0,2)$ & 1 & $(1,6)$ & 7 & $(0,4)$ \\
\hline Falla cardiopulmonar & 1 & $(1,6)$ & - & - & - & & - & - & - & - & 1 & $(0,1)$ \\
\hline Muerte & - & - & 1 & $(1,7)$ & - & & - & - & - & - & 1 & $(0,1)$ \\
\hline Otros eventos & - & - & 1 & $(1,7)$ & 13 & $(2,1)$ & 20 & $(2,4)$ & 2 & $(3,2)$ & 36 & $(2,2)$ \\
\hline Cualquiera & 15 & $(23,8)$ & 3 & $(5,1)$ & 29 & $(4,8)$ & 45 & $(5,3)$ & 3 & $(4,8)$ & 95 & $(5,8)$ \\
\hline
\end{tabular}




\section{¿Qué eficacia ha demostrado tener la quimioprofilaxis post exposición contra Bordetella pertussis?}

H. Dodhia y E. Miller ${ }^{36}$ en el Reino Unido, han hecho una búsqueda crítica de evidencia para responder esta pregunta. Catorce fueron las publicaciones seleccionadas por estos autores, que miden la eficacia de administrar eritromicina en la prevención de casos secundarios de coqueluche entre los contactos en el hogar. De ellas, sólo una ${ }^{37}$ cumple el estándar de estu- dio controlado, doble ciego y randomizado; 2 son ensayos randomizados, 4 reportes analíticos (Tabla 3 ) y 7 representan experiencias de QP en el manejo de brotes sin un diseño experimental acabado. En forma resumida, Dodhia y Miller concluyeron que:

- La evaluación ha sido hecha en el escenario de contactos que cohabitan bajo el mismo techo (households).

- La evidencia de mayor peso por su calidad metodológica es la de S.A. Halperin y $\operatorname{col}^{37}$.

Tabla 3.- Resumen de estudios analíticos sobre eficacia de la quimioprofilaxis con eritromicina en coqueluche*.

\begin{tabular}{|c|c|c|c|c|}
\hline Autores. Año & Población en estudio. País & Diseño experimental & Parámetros medidos & Efecto de eritromicina \\
\hline $\begin{array}{l}\text { de Serres y cols } \\
1995 \\
\text { (citado en ref } 36)\end{array}$ & Contactos en hogar. Canadá & Cohorte (n: 904) & $\begin{array}{l}\text { Tasa de ataque en familias } \\
\text { con/sin profilaxis }\end{array}$ & $\begin{array}{l}\text { Tasa de ataque } 17 \% \text { con QP } \\
\text { Tasa de ataque } 25 \% \text { sin QP } \\
\text { RR: 0,69 } \\
\text { (IC 95\%: 0,52-0,93) }\end{array}$ \\
\hline $\begin{array}{l}\text { Sprauer y cols } \\
1992 \\
\text { (citado en ref } 36)\end{array}$ & Contactos en el hogar. E.U.A. & Cohorte (n: 184) & $\begin{array}{l}\text { Hogares sin y con } \\
\text { casos secundarios }\end{array}$ & $\begin{array}{l}\text { a) Reciben QP: } 100 \% \text { vs } 76 \% \text { sin/con } \\
\text { casos secundarios en hogares. } \\
\text { b) QP antes de } 21 \text { días: } 97 \% \text { en } \\
\text { hogares sin casos secundarios vs } 47 \% \\
\text { en hogares con casos secundarios. } \\
\text { p }<0,001\end{array}$ \\
\hline $\begin{array}{l}\text { Steketee y cols } \\
1988 \\
\text { (citado en ref } 36)\end{array}$ & $\begin{array}{l}\text { Institución para minusválidos. } \\
\text { E.U.A. }\end{array}$ & Cohorte (n: 278) & $\begin{array}{l}\text { Tasas de ataques con QP } \\
\text { iniciada }<2 \text { semanas vs } \\
>4 \text { semanas desde inicio } \\
\text { caso primario }\end{array}$ & $\begin{array}{l}\text { Tasa de ataque en QP precoz: } 16 \% \\
\text { Tasa de ataque en QP tardía: } 75 \% \\
\text { RR 4,70 } \\
\text { (IC 95\%: } 3,36-6,57 \text { ) }\end{array}$ \\
\hline $\begin{array}{l}\text { Beillik y cols } \\
1988 \\
\text { (citado en ref } 36)\end{array}$ & Contactos en el hogar. E.U.A. & Caso-control (n: 685) & $\begin{array}{l}\text { Hogares sin y con } \\
\text { casos secundarios, } \\
\text { tardanza en inicio de } \\
\text { terapia y QP }\end{array}$ & $\begin{array}{l}\text { a) Intervalo entre inicio de terapia y la } \\
\text { aparición de caso primario: } 10,9 \text { días } \\
\text { en hogares sin casos secundarios vs } \\
23,6 \text { días en contactos con casos } \\
\text { secundarios. } p<0,001 \\
\text { b) Intervalo entre inicio de QP y la } \\
\text { aparición de caso primario: } 14,4 \text { días } \\
\text { en contactos sin casos secundarios vs } \\
22,6 \text { días en contactos con casos } \\
\text { secundarios. } p<0,02\end{array}$ \\
\hline $\begin{array}{l}\text { Halperin y cols } \\
1999 \text { (ref 37) }\end{array}$ & Contactos en hogar. Canadá & $\begin{array}{l}\text { Randomizado, doble ciego, } \\
\text { placebo-controlado ( } \mathrm{n}: 362 \text { ) }\end{array}$ & $\begin{array}{l}\text { Coqueluche cultivo }(+) \text {. } \\
\text { Respuesta serológica. } \\
\text { Síntomas. Adherencia a QP. } \\
\text { Reacciones adversas }\end{array}$ & $\begin{array}{l}\text { a) Cultivo (+): 6,6\% con QP vs } 20,3 \% \\
\text { sin QP } \\
\text { Eficacia QP: } 67 \% \text { (IC } 95 \% \text { : } 7,6-88,7 \text { ) } \\
\text { b) Síntomas: } 68,1 \% \text { con QP vs } 76,5 \% \\
\text { sin QP (p 0,14). } \\
\text { c) Duración de síntomas: } 61,8 \text { días con } \\
\text { QP vs } 46,6 \text { días sin QP (p 0,87). } \\
\text { d) Adherencia similar en ambos grupos. } \\
\text { e) Efectos adversos: } 34,0 \% \text { con QP vs } \\
\text { 15,7\% sin QP (principalmente diarrea } \\
\text { y náuseas) }\end{array}$ \\
\hline
\end{tabular}

* Adaptado de Dohdia y Miller (ref 36) y Halperin y cols (ref 37) 
- La QP reduce la tasa de casos secundarios desde 25 a $17 \%$.

- La QP, si bien reduce la frecuencia de enfermedad, no previene la infección (existe seroconversión en quienes la reciben)

- Para ser eficaz, la QR debe administrarse antes de 21 días desde el inicio de los síntomas en el caso índice; en estas condiciones se ha logrado reducir la tasa de casos secundarios desde 29 a $11 \%$.

- Debe iniciarse antes de aparecer un caso secundario; con ello se reduce la tasa de ataque secundario desde 35 a 4\% (RR 0,11 IC 95\%: 0,06-0,22).

S.A. Halperin y cols ${ }^{37}$ describen en su ensayo que la eficacia de la QP con eritromicina estolato es de 67\% utilizando como definición de caso aquellos con cultivo positivo pero nula para la prevención de casos secundarios definidos por la presencia de síntomas independiente del resultado del cultivo, lo que en otras palabras apunta a que la QP negativiza el cultivo faríngeo pero no interfiere en la producción de los síntomas, su frecuencia y su duración cuando es iniciada luego de 12 días de tos paroxística en el caso índice (Tabla 4). El insuficiente tamaño de la muestra de este ensayo podría haber influido en la imposibilidad de demostrar eficacia de la QP desde el punto de vista de la sintomatología. Este concepto es importante destacarlo para el médico tratante cuya primera intención, al indicar la QP, es evitar los molestos síntomas ocasionados por la coqueluche al individuo que entra en contacto con un caso índice. En este estudio los autores discuten que no está clara cual sería la eficacia de la QP con un inicio precoz.
Y como corolario, comentan Dodhia y Miller que la QP debe reservarse para grupos con mayor riesgo de padecer complicaciones en caso de enfermar: personas no vacunadas; lactantes hasta 12 meses de edad (en forma independiente de su estado de vacunación); mujeres embarazadas en el tercer trimestre por una mala tolerancia de la enfermedad a esta altura de la gestación y a la vez, por el riesgo de contagiar a su neonato; y senescentes por las razones antes expuestas.

Recientemente, una publicación de la Cochrane Library sobre uso terapéutico y profiláctico de antimicrobianos en coqueluche refuerza este concepto al concluir textualmente. "la evidencia es insuficiente para determinar el beneficio de la quimioprofilaxis en los contactos de coqueluche" ${ }^{38}$.

Conclusión: la QP contra coqueluche es de eficacia clínica (limitada), siempre y cuando se administre tempranamente. En la práctica cotidiana, su prescripción es comúnmente tardía y entonces no evita mayormente la aparición de casos secundarios. Debe focalizarse, a juicio del autor, en lactantes, mujeres embarazadas, senescentes, pacientes con incapacidad funcional cardiopulmonar crónica y en los contactos genuinos de ellos.

A esta altura estimo oportuno hacer una reflexión acerca de la variada interacción que $B$. pertussis establece con los hospederos. Con el advenimiento de la técnica de RPC, altamente sensible y específica ${ }^{39,40}$, con el seguimiento serológico de $\operatorname{contactos}^{41}$, y con el uso masivo de la IFD, (desprestigiada como una técnica inespecífica, poco sensible y cargada de falsos positivos), se ha podido establecer que, como sucede

Tabla 4. Presencia y duración de síntomas en contactos de pacientes con coqueluche sometidos a profilaxis con eritromicina y en controles. (Adaptado de ref 37 )

Síntoma

\begin{tabular}{|c|c|c|c|c|c|c|}
\hline \multirow[t]{2}{*}{ Síntoma } & \multicolumn{3}{|c|}{ Número que reporta síntomas } & \multicolumn{3}{|c|}{$\begin{array}{c}\text { Duración promedio (días) } \\
\text { de los síntomas }\end{array}$} \\
\hline & $\begin{array}{l}\text { Eritromicina } \\
\quad(n: 144)\end{array}$ & $\begin{array}{l}\text { Placebo } \\
\text { (n: 166) }\end{array}$ & $\mathbf{P}$ & Eritromicina & Placebo & $\mathbf{P}$ \\
\hline Cualquiera & 98 & 127 & 0,14 & 61,8 & 46,6 & 0,87 \\
\hline Congestión nasal & 83 & 93 & 0,86 & 39,1 & 40,2 & 0,96 \\
\hline Tos (cualquier tipo) & 88 & 110 & 0,45 & 53,8 & 46,4 & 0,25 \\
\hline Exacerbación nocturna & 50 & 70 & 0,32 & 38,6 & 38 & 0,87 \\
\hline Paroxística & 31 & 41 & 0,55 & 37,1 & 50,5 & 0,17 \\
\hline Emetizante & 13 & 31 & 0,03 & 24,8 & 28,5 & 0,71 \\
\hline Whoop inspiratorio & 10 & 22 & 0,08 & 34,9 & 21 & 0,46 \\
\hline Apnea & 1 & 4 & 0,2 & 8 & 19,3 & 0,71 \\
\hline Cianosis & 1 & 1 & 0,91 & 79 & 15 & 0,32 \\
\hline
\end{tabular}

Número que reporta síntomas
Duración promedio (días) de los síntomas 
con tantas otras enfermedades infecciosas, la coqueluche "florida en síntomas y signos" representa la cúspide de una pirámide en cuyos niveles inferiores y con mayor frecuencia, se pueden reconocer otras expresiones de infección por B. pertussis (Figura 1): la forma clínica del adolescente y adulto ${ }^{42-44}$; oligosintomática o abortiva del lactante vacunado ${ }^{41,45,46}$; la bordetelosis caracterizada por un catarro respiratorio alto inespecífico y transitorio; y la portación transitoria $^{39,47}$ (Figura 1). Ninguna de ellas cumple con los criterios establecidos por la OMS o el CDC de Atlanta para notificar un caso de coqueluche. De tal manera que junto a cada caso clínico que cumple con la definición de caso sospechoso o de caso confirmado y que motivará una acción de QP, es esperable la existencia de innumerables hospederos que están excretando $B$. pertussis en forma más o menos intensa y prolongada; probablemente estas formas de infección tienen un peso menor que el cuadro clínico típico en la transmisión de la infección pero, en definitiva participan en la perpetuación de la coqueluche en poblaciones con adecuadas coberturas de vacunación. Entonces, pretender evitar nuevos casos o frenar un brote de coqueluche en base a QP ofrecida en el entorno de los casos índices se convierte en un "sacar agua a canastos".

Conclusión: El resultado esperable de la QP será magro y el impacto negativo de una aplicación indiscriminada y, a veces repetitiva, de macrólidos, es ciertamente motivo de preocupación; estas dos condiciones obligan a replantearse la racionalidad de la QP en coqueluche.

\section{¿Cuánto tiempo demora el macrólido en negativizar el cultivo de $\boldsymbol{B}$. pertussis?}

Ensayos bien reglados han establecido la negativización del cultivo en 5 días de tratamiento con macrólidos ${ }^{48}$. No se dispone de información acabada respecto al efecto erradicador que tendrían cotrimoxazol $^{38,49,50}$ y las cefalosporinas de tercera generación, si bien todos estos antimicrobianos son activos in vitro sobre B. pertussis p $^{49,51,52}$.

\section{Duración de los esquemas de quimioprofilaxis}

Si tomamos como base que 7 días de estolato de eritromicina son tan eficaces en erradicar B. pertussis de la nasofaringe como 14 días en pacientes sintomáticos ${ }^{53}$, el mismo plazo puede ser extrapolado a la QP. El plazo actualmente recomendado en la normativa nacional para la QP en contactos de un caso índice es de 7 días $^{24}$. En este mismo sentido, ensayos terapéuticos de eficacia bacteriológica con claritromicina 7 días $^{54}$ y con azitromicina 5 días $^{55}$, pueden aplicarse en esquemas de QP.

\section{Tolerancia de macrólidos y su impacto en la adherencia}

Sabida es la irritación gastrointestinal causada por eritromicina, "efecto motilina" que ha sido aminorado al modificar la molécula en los nuevos macrólidos y azálidas, especialmente miocamicina y azitromicina ${ }^{55}$. La intolerancia gástrica es causa frecuente del abandono de una QP anti pertussis motivando un mayor incumplimiento de la prescripción médica. En una situación epidemiológica casi experimental, en un contingente militar estrechamente supervigilado se constató que $35 \%$ no toleró la administración de eritromicina estolato, prescrita por 14 días, y abandonó su cumplimiento ${ }^{56}$. Esquemas abreviados de QP con eritromicina, y/o que emplean azitromicina o claritromicina, auguran un mejor cumplimiento de la indicación y una menor pérdida de recursos farmacéuticos.

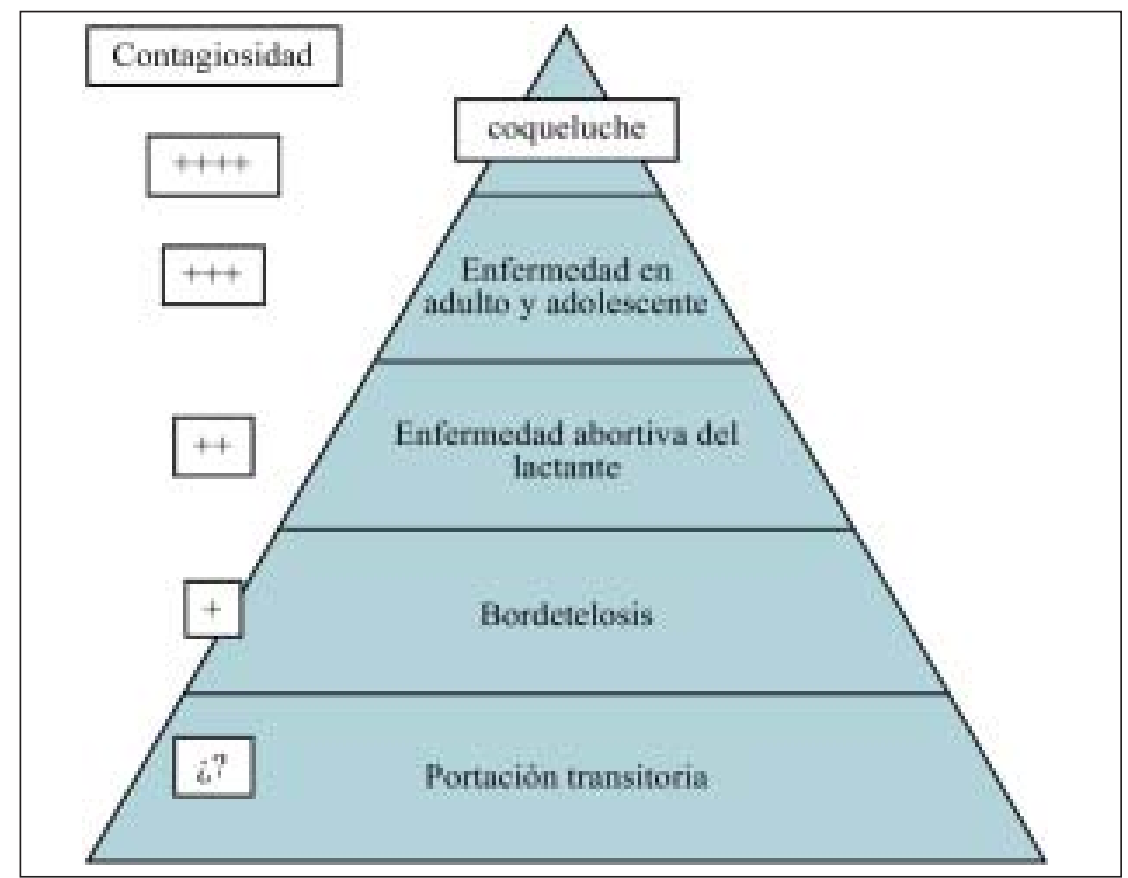

Figura 1. Formas de interacción entre Bordetella pertussis y el Hombre. Contagiosidad atribuible a cada una. En forma hipotética, en coqueluche la fuente de contagio es múltiple. Probablemente quien más tose es más contagiante y, en el otro extremo, quien se comporta como un silencioso portador transitorio, no represente una fuente de contagio significativa y no deba recibir terapia de erradicación. 


\section{Propuesta del autor para administrar la quimioprofilaxis ajustada a los antecedentes expuestos}

Contactos en el hogar. La QP está indicada a:

- Contactos de un caso índice "que viven bajo su mismo techo", si en el grupo existe un hospedero de alto riesgo. Deben cumplirse dos condiciones para garantizar la eficacia de la QP:

- Iniciarla antes de cumplirse 21 días de síntomas en el caso índice y,

- siempre y cuando no se haya producido ya un caso secundario en el grupo.

Se consideran de alto riesgo para cursar con una enfermedad grave y complicada:

- Lactantes bajo 12 meses de edad o con $<3$ dosis de vacunación.

- Pacientes con afecciones cardíacas/pulmonares crónicas determinantes de incapacidad funcional.

- Personas senescentes.

- La mujer embarazada que cursa con un último trimestre de gestación. Se incluye en este grupo de riesgo pues puede tener una mala tolerancia de la enfermedad y, por otra parte, puede constituir una fuente significativa de infección para su neonato.

Contactos hospitalarios en sala común. Está indicado efectuar QP en los pacientes que comparten sala con el caso índice y tienen menos de 3 dosis de vacuna anti-pertussis. Como medida complementaria, debe mantenerse un aislamiento aéreo en cohorte del caso índice y sus contactos hasta haber completado 5 días de macrólidos.

Paciente ingresado a Unidad de Cuidados Intensivos. Idealmente debe ubicarse en unidad de aislamiento hasta completar el tratamiento erradicador de $B$. pertussis. En todo caso, debe entenderse que el paciente con coqueluche sometido a intubación naso $\mathrm{u}$ oro-traqueal probablemente no representa una fuente de contagio para el resto de los pacientes en esta unidad y, de ser necesario su ingreso a UCI para recibir soporte con ventilación mecánica, puede prescindirse de su aislamiento aéreo. Por otra parte, el personal que efectúa la aspiración de sus secreciones debe usar mascarilla hasta cumplirse 5 días de terapia con macrólidos.

Adultos que laboran con niños. Si bien no tienen alto riesgo de cursar con una enfermedad complicada, aquellos adultos expuestos a la coqueluche y que trabajan con poblaciones que sí tienen este alto riesgo, por ejemplo funcionarios de sala cuna y jardines infantiles, o personal de salud de servicios críticos como neonatología y UCI, debieran ser inmunizados con una vacuna anti-pertussis apropiada para adultos (pronta a estar disponible en nuestro medio) y así aminorar la posibilidad de comportarse como reservorios y vehículos de infección. La prescripción de QP en estas personas, que según el CDC de Atlanta, estaría indicada ${ }^{31 a}$, entraña los mismos inconvenientes y reparos que su uso en la población general: mala tolerancia, baja adherencia, dificultades en la selección de los genuinos contactos, impacto psicológico y ansiedad injustificados, indicación reiterada de QP en un mismo funcionario, riesgos de inducir resistencia a macrólidos en la microbiota de estas personas, cuestionamiento sobre su eficacia, etc

\section{Esquemas de quimioprofilaxis}

- Eritromicina succinato*: $50-60 \mathrm{mg} / \mathrm{kg} /$ día fraccionada cada 6 a 8 horas, durante 7 días. Cada dosis debe ser administrada en forma post-prandial para optimizar su absorción, en estas condiciones puede asimilarse la eficacia bacteriológica del etilsuccinato a la descrita para estolato de eritromicina ${ }^{57,58}$.

- Claritromicina: $15 \mathrm{mg} / \mathrm{kg} /$ día fraccionada cada 12 horas, durante 7 días.

- Azitromicina: $10 \mathrm{mg} / \mathrm{kg}$ en una dosis el primer día, seguido de $5 \mathrm{mg} / \mathrm{kg} / \mathrm{día}$ en una dosis desde el segundo al quinto día. Total: 5 días.

\section{Resumen}

La quimioprofilaxis $(\mathrm{QP})$ en coqueluche debe orientarse a proteger personas con riesgo de presentar complicaciones graves o fallecer: neonatos y lactantes bajo un año, senescentes, pacientes con afecciones cardiacas y pulmonares con insuficiencia funcional, y mujeres en tercer trimestre de embarazo (para proteger al neonato). La evidencia disponible permite recomendar una QP selectiva en los contactos ocurridos en el hogar, hasta 21 días de aparecer el caso primario, y antes de presentarse un caso secundario, recomendación que puede hacerse extensible a personas con alto riesgo que co-habitan con un caso índice en el hospital, guarderías infantiles y hogares de ancianos. La transmisibilidad de $B$. pertussis podría alcanzar una distancia mayor de 1,5 metros desde la cara del paciente, concepto importante para diseñar la QP en el medio hospitalario. Sólo existen argumentos sólidos para emplear macrólidos y azálidas; siete días es un plazo suficiente para erradicar $B$. pertussis con eritromicina o claritromicina, 5 días para azitromicina. 


\section{Referencias}

1.- Schito GC. Is antimicrobial resistance also subject to globalization? Clin Microbiol Infect 2002; 8 Suppl 3:1-8; discussion 33-5.

2.- Freeman A, Shulman S. Macrolide resistance in group A Streptococcus. Pediatr Infect Dis J 2002; 21: 1158-1160.

3.- Klugman KP, Lonks JR. Hidden epidemic of macrolide-resistant pneumococci. Emerg Infect Dis 2005; 11: 802-7.

4.- Seppala H, Klaukka T, Vuopio-Varkila J, Muotiala A, Helenius H, Lager K, et al. The effect of changes in the consumption of macrolides on the erythromycin resistance in the group A streptococci in Finland. Finnish Study Group for Antimicrobial resistance. N Engl J Med 1997; 337: 441-6

5.- Tamayo J, Perez-Trallero E, Gomez-Garces JL, Alos JI; Spanish Group for the Study of Infection in the Primary Health Care Setting. Resistance to macrolides, clindamycin and telithromycin in Streptococcus pyogenes isolated in Spain during 2004. J Antimicrob Chemother 2005; 56: 780-2.

6.- Maruyama S, Yoshioka H, Fujita K, Takimoto M, Satake Y. Sensitivity of group A streptococci to antibiotics. Prevalence of resistance to erythromycin in Japan. Am J Dis Child 1979; 133: 1143-5.

7.- Jacobs MR. Streptococcus pneumoniae: Epidemiology and patterns of resistance. Am J Med 2004: 117 (Suppl 3A): 3-15S.

8.- Jacobs MR, Felmingham D, Appelbaum PC, Gruneberg RN; The Alexander Project Group. The Alexander Project 1998-2000: susceptibility of pathogens isolated from community-acquired respiratory tract infection to commonly used antimicrobial agents. J Antimicrob Chemother 2003; 52: 229-46.

9.- Prado V, Lopardo H, Sader H, Trujillo H, Zurita J, Arzate P, et al. Resistencia a macrólidos en cepas de Streptococcus pyogenes aisladas de infecciones pediátricas en 6 centros latinoamericanos: aspecrtos epidemiológicos y moleculares. Libro de Resúmenes XVIII Congreso Chileno de Infectología, Pucón 23-26 de agosto de 2001. Abstr P64, pág 83.

10.- Palavecino E, Riedel I, Berrios X, Bajaksouzian S, Johnson D, Kaplan E, et al. Prevalence and mechanisms of macrolide resistance in Streptococcus pyogenes in Santiago, Chile. Antimicrob Agents Chemother 2001; 45: 339-41.

11.- Camponovo R. Problemas de resistencia en Streptococcus pyogenes. Rev Chil Infect 2002; 19 (Supl 2): 107-10.

12.- González P. Vigilancia de la resistencia a antimicrobianos. Rev Chil Infect 2002; 19
(Supl 2): 135-9.

13. - Palavecino E. Puesta al día en el estudio de susceptibilidad de Streptococcus pneumoniae. Rev Chil Infect 2002; 19 (Supl 2): 101-6.

14.- Vergara R, López I, Navarro S, Letelier S, Gaete E, Gil ME, et al. Características clínicas, bacteriológicas y epidemiológicas de enfermedad neumocócica invasiva em niños de Valparaíso. Libro de Resúmenes XIX Congreso Chileno de Infectología, Santiago, 17-19 de noviembre de 2002. Abstr PO53, pág 61 .

15.- Skarmeta M, Czechowitz J, Lima A, Maldonado A, Seoane M, Hormazábal JC, et al. Susceptibilidad de 404 cepas invasoras de Streptococcus pneumoniae a 16 antimicrobianos determinada mediante el kit comercial MICroSTREP®. Libro de Resúmenes XXII Congreso Chileno de Infectología, Puerto Varas, 26-29 de octubre de 2005. Abstr CO7, pág 35.

16.- Lewis K, Saubolle MA, Tenover FC, Rudinsky MF, Barbour SD, Cherry JD. Pertussis caused by an erythromycinresistant strain of Bordetella pertussis. Pediat Infect Dis J 1995; 14; 388-91.

17.- Korgenski EK and Daly JA. Surveillance and detection of resistance in Bordetella pertussis isolates recovered from a pediatric population in the Intermountain West region of the United States. J Clin Microbiol 1997; 35: 2989-91.

18.- Hill BC, Baker CN, Tenover FC. A simplified method for testing Bordetella pertussis for resistance to erythromycin and other antimicrobial agents. J Clin Microbiol 2000; 38: 1151-5.

19.- Pumarino G, Mihalic V, González P, Andrade W, Rojas T. Evaluación de susceptibilidad antimicrobiana de Bordetella pertussis aisladas a partir de muestras clínicas. Libro de Resúmenes. XXI Congreso Chileno de Infectología. Viña del Mar 13-16 de octubre de 2004. Abstr. CO42, pág 62.

20.- Summary on Infectious Diseases: Pertussis. American Academy of Pediatrics. In Pickering L (ed). 2003 Red Book: Report of the Committee on Infectious Diseases. $26^{\text {th }}$ ed. American Academy of Pediatrics Elk Grove Village, Il, 2003: 472-86.

21.- NHMRC-National Health and Medical Research Council. Pertussis en: The Australian Immunisation Handbook $8^{\text {th }}$ ed. 2003. http://www.nhmrc.gov.au/publications/ subjects/communicable.htm. (accedido octubre 5, 2005).

22.- Dodhia H, Crowcroft NS, Bramley JC, Miller E. UK guidelines for use of erythromycin chemoprophylaxis in persons exposed to pertussis. J Public Health Med 2002; 24: 200-6.
23.- National Consensus Conference on Pertussis. Canada Communicable Disease Report. 2003 (April). Volume 2953. http://www.hcsc.gc.ca/pphb-dgspsp (Accedido octubre 5, 2005).

24. - Ministerio de Salud de Chile. http:// epi.minsal.cl/epi/html/normas/circul/ Circular-Coqueluche.pdf (Accedido octubre 5, 2005).

25.- Mortimer EA Jr. Pertussis and its prevention: a family affair. J Infect Dis. 1990; 161: 473-9. Comment on: J Infect Dis. 1990; 161: 480-6. J Infect Dis. 1990; 161: 487-92.

26. - Mertsola J, Ruuskanen O, Eerola E, Viljanen MK. Intrafamiliar spread of pertussis. J Pediatr 1983: 103: 359-63.

27. - Long SS, Welkon CJ, Clark JL. Widespread silent transmission of pertussis in families: antibody correlates of infection and symptomatology. J Infect Dis 1990; 161: 480-6.

28.- de Serres G, Boulianne N, Douville Fradet M, Duval B. Pertussis in Quebec: ongoing epidemic since the late 1980s. Can Commun Dis Rep 1995; 21: 45-8.

29. - Weiss AA, Hewlett EL. Virulence factors of Bordetella pertussis. Ann Rev Microbiol 1986; 40-661-8.

30.- Garner JS, Hospital Infection Control Practices Advisory Committee. Guideline for isolation precautions in hospitals. Infect Control Hosp Epidemiol 1996; 17: 53-90.

31.- Aintablian N, Walpita P and Sawyer M. Detection of Bordetella pertussis and respiratory syncytial virus in air samples from hospital rooms. Infect Control Hosp Epidemiol 1998; 19: 918-23.

31a.- Guidelines for preventing health-care-associated pneumonia, 2003: Recommendations of $\mathrm{CDC}$ and the Healthcare Infection Control Practices Advisory Committee. MMWR Recomm Report 2004 Mar 26; 53 (RR-3): 1-36.

32.- Heininger U, Klich K, Stehr K. Cherry JD. Clinical findings in Bordetella pertussis infection: Results of a prospective multicenter surveillance study. Pediatrics 1997; 100: E10

33. - Mikelova LK, Halperin SA, Scheifele D, Smith B, Ford-Jones E, Vaudry W, et al. Predictors of death in infants hospitalized with pertussis: a case-control study of 16 pertussis deaths in Canada. J Pediatr 2003; 143: 576-81.

34.- Vitek CR, Pascual FB, Baughman AL, Murphy TV. Increase in deaths from pertussis among young infants in the United States in the 1990s. Pediatr Infect Dis J 2003; 22: 628-34.

35.- Mertens PL, Stals FS, Schellekens JF, Houben AW, Huisman J. An epidemic of 
pertussis among elderly people in a religious institution in The Netherlands. Eur J Clin Microbiol Infect Dis 1999; 18: 242-7.

36.- Dodhia H, Miller E. Review of the evidence for the use of erythromycin in the management of persons exposed to pertussis. Epidemiol Infect 1998; 120: 1439.

37.- Halperin SA, Bortolussi R, Langley JM, Eastwood BJ, de Serres G. A randomized, placebo-controlled trial of erythromycin estolate chemoprophylaxis for household contacts of children with culture-positive Bordetella pertussis infection. Pediatrics 1999; 104: e42.

38.- Altunaiji S, Kukuruzovic R, Curtis N, Massie J. Antibiotics for whooping cough (pertussis). Cochrane Database Syst Rev 2005 Jan 25; (1): CD004404.

39.- Heininger U, Schmidt-Schlämpfer G, Cherry JD and Stehr K. Clinical validation of a polymerase chain reaction assay for the diagnosis of pertussis by comparison with culture, serology and symptoms during a large pertussis vaccine efficacy trial. Pediatrics 2000; 105: E31.

40.- Schutter I, Malfroot A, Dab I, Hoebrekx N, Muyldermans G, Pierard D, et al. Molecular typing of Bordetella pertussis isolates recovered from Belgian children and their household members. Clin Infect Dis 2003; 36: 1391-6.

41.- Long SS, Lischner HW, Deforest A, Clark JL. Serologic evidence of subclinical pertussis in immunized children. Pediatr Infect Dis J 1990; 9: 700-5.

42.- Senzilet LD, Halperin SA, Spika JS, Alagaratnam M, Morris A, Smith B; Sentinel Health Unit Surveillance System Pertussis
Working Group. Pertussis is a frequent cause of prolonged cough illness in adults and adolescents. Clin Infect Dis. 2001; 32: 1691-7.

43. - de Serres G, Shadmani R, Duval B, Boulianne N, Dery P, Douville Fradet M, et al. Morbidity of pertussis in adolescents and adults. J Infect Dis 2000; 182: 174-9.

44.- Cofré J. Coqueluche en adultos y adolescentes. Rev Chil Infect 2003; 20 (Supl 1): S52 - S58.

45.- Schlapfer G, Sen H, Berger R, Just M. Use of the polymerase chain reaction to detect Bordetella pertussis in patients with mild or atypical symptoms of infection. Eur J Clin Microbiol Infect Dis 1993; 12: 459-63.

46.- Schellekens Joop, Wirsing von König CH, Gardner P. Pertussis sources of infection and routes of transmission in the vaccination era. Pediatr Infect Dis J 2005; 24 (5 Suppl): S19-S24.

47.- Klement E, Iliuel L, Engel I, Hasin T, Yavzori M, Orr N et al. An outbreak of pertussis among young Israeli soldiers. Epidemiol Infect 2003; 131: 1049-54.

48. - Bergquist SO, Bernarder S, Dahnsjo H, Sundelof B. Erythromycin in the treatment of pertussis: a study of bacteriologic and clinical effects. Pediatr Infect Dis J 1987; 6: 458-61. Erratum Pediatr Infect Dis J 1987; 6: 1035 .

49.- Brett M, Short P, Beatson S. The comparative in-vitro activity of roxithromycin and other antibiotics against Bordetella pertussis. J Antimicrob Chemother 1998; 41 Suppl B: 23-7

50.- Hoppe JE, Halm U, Hagedorn HJ, KraminerHagedorn A. Comparison of erythromycin ethylsuccinate and co-trimoxazole for treatment of pertussis. Infection. 1989; 17:
227-31. Erratum in: Infection 1989; 17: 330 .

51.- Bannatyne RM, Cheung R. Susceptibility of Bordetella pertussis to cephalosporin derivatives and imipenem. Antimicrob Agents Chemother 1984; 26: 604-5.

52.- Hoppe JE, Müller J. In vitro susceptibility of Bordetella pertussis and Bordetella parapertussis to six new oral cephalosporines. Antimicrob Agents Chemother 1990; 34: 1442-3.

53.- Halperin SA, Bortolussi R, Langley JM, Miller B, Eastwood BJ. Seven days of erythromycin estolate is as effective as fourteen days for the treatment of Bordetella pertussis infections. Pediatrics 1997; 100: 65-71.

54.- Aoyama T, Sunakawa K, Iwata S, Takeuchi Y, Fujii R. Efficacy of short-term treatment of pertussis with clarithromycin and azithromycin. J Pediatr 1996; 129; 761: 4.

55. - Langley JM, Halperin SA, Boucher FD, Smith B; Pediatric Investigators Collaborative Network on Infections in Canada (PICNIC). Azithromycin is as effective as and better tolerated than erythromycin estolate for the treatment of pertussis. Pediatrics. 2004; 114: e96-101.

56.- Purcell BK, Doodley DP, Grau PJ, Hill KJ, Oliverson FW. Experience with directly observed prophylaxis using erythromycin in military. Military Medicine 2004; 169: 417-20

57.- Bass JW. Pertussis: current status of prevention and treatment. Pediatr Infect Dis 1985; 4: 614-9.

58.- The Erythromycin Study Group, Hoppe JE. Comparison of erythromycin estolate and ethylsuccinate for treatment of pertussis. Pediatr Infect Dis J 1992; 11: 189-93. 